\title{
Surgical management of stress urinary incontinence: A rational approach to treatment selection
}

\author{
J. Christian Winters, MD, FACS
}

H. Eustis Reily Professor of Urology and Gynecology, Louisiana State University Health Sciences Center, New Orleans, LA

Cite as: Can Urol Assoc J 2012;6(5):S1 18-9. http://dx.doi.org/10.5489/cuaj.12232

\section{Abstract}

There are a number of operative approaches to correct stress urinary incontinence (SUI). There is clearly not one procedure that "fits all." This review provides a summary of key available data comparing the various interventions. These findings are then incorporated into an algorithm, which attempts to outline a rational approach to select the most appropriate procedures in women seeking surgical treatment of SUI.

$\mathrm{T}$ here are many different surgical interventions that can be considered for women with stress urinary incontinence (SUI). Recent expert consensus (e.g., the 2009 clinical guidelines from the American Urological Association $[A \cup A]^{1}$ ) states that 48-month cure rates are similar for retropubic suspensions, autologous slings and retropubic midurethral slings (RPMUS), and each of these is a desirable treatment option. It thus falls to the clinician to help select the most appropriate intervention for each individual patient. This review will briefly summarize some of the more compelling clinical-trial and meta-analytic evidence in this area, and propose an algorithm to help guide the decision-making process.

\section{Head-to-head comparative trials}

\section{Burch colposuspension vs. autologous sling}

To date, a number of studies have compared the Burch colposuspension to sling procedures. Perhaps the most notable is the SISTEr Trial comparing the Burch to the autologous pubovaginal sling (PVS). ${ }^{2}$ In this multicentre, randomized clinical trial involving 655 women with stress incontinence, the 24 -month success rate (success defined as negative pad test, no urinary incontinence [as recorded in a three-day diary], a negative cough and Valsalva stress test, no self-reported symptoms, and no retreatment for the condition) was higher for women who underwent the sling procedure than for those who underwent the Burch procedure $(47 \%$ vs. $38 \%$, $p=0.01$ ). The investigators also looked at SUI-specific success (negative cough and Valsalva stress test, no self-reported symptoms, and no retreatment for the condition). This success rate was also higher for the autologous sling ( $66 \%$ vs. $49 \%, p=0.01)$. However, complications were more frequent among those who underwent the sling procedure. These included urinary tract infections (UTIs), difficulty voiding, and postoperative urge incontinence.

\section{Midurethral tapes vs. burch}

In 2010, Novara performed a meta-analysis of the existing literature comparing midurethral tapes with retropubic suspensions. ${ }^{3} \mathrm{~A}$ total of 39 randomized, controlled trials were reviewed. The results showed that midurethral tapes had significantly higher overall and objective cure rates compared with Burch procedures (odds ratios [OR] 0.61 and 0.38 , respectively; both $p<0.0001)$. However, midurethral tapes were also associated with a higher risk of bladder perforations (OR: 4.94; $p<0.0001$ ).

\section{Which sling?}

Taken in aggregate, the apparent weight of the available evidence suggests that sling procedures are probably more efficacious than retropubic bladder neck suspensions. When comparing sling procedures, the efficacy of the autologous PVS and the midurethral sling (MUS) appears similar. A Cochrane review concluded that MUS have similar efficacy to traditional pubovaginal slings, but with the advantages of shorter operating time, less postoperative voiding dysfunction, and fewer de novo urgency symptoms. ${ }^{4}$

A number of studies have compared RPMUS to transobturator slings (TOT). The most compelling prospective evidence of this kind comes from the Trial Of Midurethral Slings (TOMUS). ${ }^{5}$ This study included 597 women with SUI, and the primary outcome was treatment success at 12 months (negative stress test, negative pad test, self-reported absence of symptoms, no leakage episodes recorded, and no re-treatment). Treatment success was achieved by $80.8 \%$ in the RPMUS group and $77.7 \%$ in the TOT-sling group $(p=N S)$. This met the prespecified criteria for equivalence. However, when only subjective success measures were examined (absence of symptoms, no leakage episodes and no re-treatment), 
the RPMUS group performed somewhat better. Although there was still no statistically significant difference between the two groups, the $95 \%$ confidence interval was wide enough that the criteria for equivalence were not met.

While the RPMUS was associated with somewhat more favourable efficacy, it has also been associated with a higher incidence of bladder perforations and voiding difficulties. ${ }^{4}$ Conversely, more groin pain and vaginal erosions are seen after TOT. ${ }^{6}$ In addition, several studies have reported that TOT procedures perform poorly when compared to RPMUS in patients with intrinsic urethral sphincter deficiency (ISD) (defined by low urethral pressures). The presence of both ISD and the lack of urethral hypermobility compounds the failure risk of MUS procedures, particularly TOT procedures.

\section{Conclusion: Proposed management algorithm}

On the whole, the evidence suggests that midurethral slings in general are the most efficacious surgical interventions to correct SUI. The literature does not, however, provide hard recommendations for which type of sling to use in any given patient.

The ideal candidate for whom any MUS would likely be effective is one with urethral hypermobility, moderate ISD, no detrusor storage abnormalities, and a healthy vaginal wall. However, there are some specific considerations that might lead one to select one type of sling over another. Absence of urethral hypermobility, for example, may place patients at higher risk of failure following tension-free vaginal tape (TVT). ${ }^{7,8}$ TOT may be less effective than TVT (or SPARC surgical procedure) in women with severely low urethral pressures. ${ }^{9,10}$ For women with ISD, RPMUS appears to be a better option, as it likely applies more urethral pressure. ${ }^{8}$

The algorithm shown in Figure 1 is a preliminary attempt to blend the available evidence with clinical experience to provide a rational visual aid for decision-making when selecting a surgical intervention for SUI.

\section{References}

1. Dmochowski RR, Blaivas JM, Gormley EA, et al. Update of AUA guideline on the surgical management of female stress urinary incontinence. J Urol 2010;183(5):1906-14. http://dx.doi.org/10.1016/i. juro.2010.02.2369

2. Albo ME, Richter HE, Brubaker $L$, et al. Burch colposuspension versus fascial sling to reduce urinary stress incontinence. N Engl J Med 2007;356(21):2143-55. http://dx.doi.org/10.1056/NEJMoa070416

3. Novara $G$, Artibani $W$, Barber MD, et al. Updated systematic review and meta-analysis of the comparative data on colposuspensions, pubovaginal slings, and midurethral tapes in the surgical treatment of female stress urinary incontinence. Eur Urol 2010;58(2):218-38. http://dx.doi.org/10.1016/i. eururo.2010.04.022

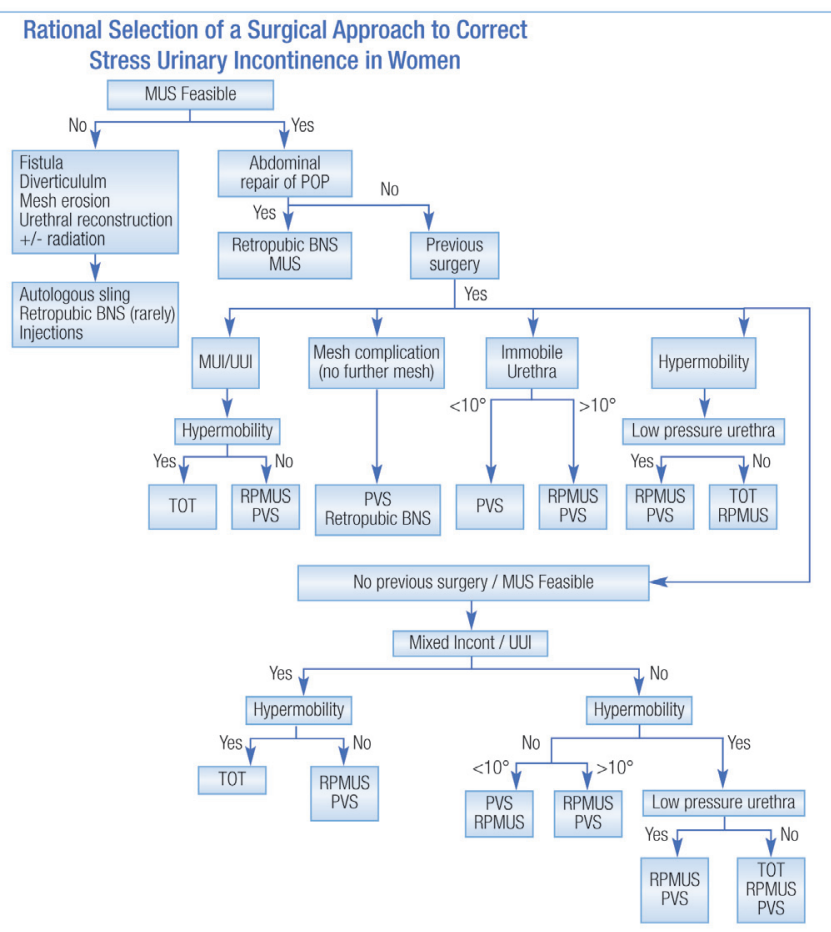

Fig. 1. Rational selection of a surgical approach to correct stress urinary incontinence in women.

4. Ogah J, Cody JD, Rogerson L. Minimally invasive synthetic suburethral sling operations for stress urinary incontinence in women. Cochrane Database Syst Rev 2009; (4):CD006375.

5. Richter HE, Albo ME, Zyczynski HM, et al. Retropubic versus transobturator midurethral slings for stress incontinence. N Engl J Med 2010;362(22):2066-76. http://dx.doi.org/10.1056/NEJMoa0912658

6. Secco S, Crestani A, Cattaneo F, et al. Slings in surgery of genuine stress incontinence. World I Urol 2011 0ct 15. [Epub ahead of print].

7. Liapis $A$, Bakas $P$, Lazaris $D$, et al. Tension-free vaginal tape in the management of recurrent stress incontinence. Arch Gynecol Obstet 2004;269(3):205-7. http://dx.doi.org/10.1007/s00404-003-0530-9

8. Lo TS, Horng SG, Chang $\mathrm{CL}$, et al. Tension-free vaginal tape procedure after previous failure in incontinence surgery. Urology 2002;60(1):57-61. http://dx.doi.org/10.1016/S0090-4295(02)01618-7

9. Miller JJ, Botros SM, AkI MN, et al. Is transobturator tape as effective as tension-free vaginal tape in patients with borderline maximum urethral closure pressure? Am J Obstet Gynecol 2006;195(6):1799804. http://dx.doi.org/10.1016/i.ajog.2006.07.011

10. O'Connor RC, Nanigian DK, Lyon MB, et al. Early outcomes of mid-urethral slings for female stress urinary incontinence stratified by valsalva leak point pressure. Neurourol Urodyn 2006;25(7):685-8. http:// dx.doi.org/10.1002/nau.20286

Competing interests: Dr. Winters is a paid consultant for Astellas and Pfizer.

Correspondence: Dr. J. Christian Winters, 1542 Tulane Ave, 5th Floor., Room 547, New Orleans, LA 70112; fax: 504-568-2307; cwinte@|suhsc.edu 